\title{
ETIOLOGY AND OUTCOME OF ESOPHAGEAL STRICTURE AMONG CHILDREN: LOCAL DATA FROM TERTIARY CARE CHILDREN HOSPITAL OF MULTAN, PAKISTAN
}

\section{Ibrar Hussain ${ }^{\natural}$, Muhammad Tariq Aziz ${ }^{2}$, Hassan Suleman', Saima Jabeen Joya', Ghazi Khan Khosa', Muhammad Abu-Talib'}

\begin{abstract}
OBJECTIVES: To find out the etiology and outcome in terms of clinical improvement among children having esophageal stricture (ES).

METHODS: This prospective study was conducted from July 2019 to March 2020 at Children's Hospital, Multan, Pakistan on diagnosed patients of ES, ageing $<15$ years. Demographic details, different etiologies, location of the ES and treatment outcome were recorded. After initial management, endoscopy and dilatation was done at 6 weeks. Patients were followed-up for at least 12 weeks.

RESULTS: Out of 32 children with ES, 19 (59.4\%) were males. Mean age of children was $36.58 \pm 19.6$ months. Twenty-four $(75 \%)$ patients had proximal and $8(25 \%)$ had distal stricture. Chemical burn $(n=23 ; 71.9 \%)$ and esophageal atresia $(n=4: 12.5 \%)$ were commonest causes of ES. Dilatation and surgery were performed in 21 (65.6\%) cases followed by dilatation only in $10(31.3 \%)$ cases and surgery alone in one $(3.1 \%)$ case. In patients with chemical burns, majority $(n=16 / 23 ; 69.6 \%)$ required both dilatation and surgery. Overall outcome of treatment options was good in $62.5 \%(n=20 / 32)$ patients. Outcome was good in $61.9 \%(n=13 / 21)$ of patients requiring both dilatation and surgery and $70 \%(n=7 / 10)$ in patients having dilatation alone $(p=0.385)$. Outcome was good in $69.6 \%(n=16 / 23)$ of patients with chemical burns and $70 \%(n=7 / 10)$ in patients with dilatation only $(p=0.385)$. Mortality rate was $3.1 \%(n=1)$.
\end{abstract}

CONCLUSION: Chemical burn and esophageal atresia were the commonest causes of ES. Outcome of all procedures was good in $62.5 \%$ cases and had no significant relationship with causes and site of ES or types of treatment.

Keywords: Esophageal Atresia (MeSH); Mortality (MeSH); Child (MeSH); Esophageal Stenosis (MeSH); Burns, Chemical (MeSH); Child, Preschool (MeSH).

THIS ARTICLE MAY BE CITED AS: Hussain I, Aziz MT, Suleman H, Joya SJ, Khosa GK, Abu-Talib M. Etiology and outcome of esophageal stricture among children: local data from tertiary care children hospital of Multan, Pakistan. Khyber Med Univ J 2020;13(2):86-90. https://doi.org/10.35845/ kmuj.2021.20915

\section{INTRODUCTION}

$\square$ sophageal stricture $(E S)$ is a rare condition among children and described as "abnormal narrowing of the esophageal lumen". 1,2 The esophagus generally lose distensibility with stricture formation that could be localized or diffused throughout the length of esophagus. Narrowing of esophageal lumen could also be due to direct invasion of malignancy or lymph node enlargement. ${ }^{2}$ Overall incidence of ES is around I. I/ 10000 annually. ${ }^{3}$
Multiple etiologies are associated with ES like congenital anomalies, esophageal atresia, inflammatory disorders, eosinophilic esophagitis, gastro-esophageal reflux disease (GERD) and caustic ingestion. ${ }^{4,5}$ A stricture could be benign or malignant. Proper management is dependent upon identification of the etiology of the ES. Among adults most of the ES are the result of benign peptic strictures from long standing GERD, accounting for approximately $70-80 \%$ of the cases, while in children ${ }^{6}$ corrosive substance ingestion is found to be the
I: Department of Paediatric Gastroenterology, Hepatology \& Nutrition, The Children's Hospital \& The Institute of Child health, Multan

2: Department of Paediatric Medicine, The Children's Hospital \& The Institute of Child Health, Multan

Contact \#: +92-32I-6899314

Email冈: ibrarhussainpmc@hotmail.com

Date Submitted: October 13,2020

Date Revised: June 04, 202।

Date Accepted: June 06, 2021

commonest leading to formation of ES. ${ }^{7}$ ES commonly presents in the form of dysphagia. Without much concerned to the etiology of the ES, prompt and aggressive approach is best advised for the restoration of luminal patency which could result into symptomatic betterment as well as palliative management among individuals having cancer. ${ }^{8}$ Recent advancements in the last few decades in the form of endoscopic management and various stent products have been found to promise heartening outcomes. Improved stricture management as well as less recurrence rates along with less number of complications are reported in the recent years among cases having ES.

To the best of our knowledge, no recent data is available from Pakistan about the etiologies as well as the outcome of pediatric population suffering with ES. This prospective study was planned to find out the etiologies and outcome in terms of clinical improvement among children having ES. Finding out pattern of etiologies and outcomes regarding current practices will help finding ways to reduce the mortality and morbidity regarding ES among children.

\section{METHODS}

This single center prospective study was conducted at The Department of Gastroenterology and Hepatology, The Children's Hospital and The Institute of Child's Health, Multan, Pakistan. All patients with ES, ageing $<15$ years, 
TABLE I: RELATIONSHIP BETWEEN CAUSES AND SITE OF ESOPHAGEAL STRICTURE $(\mathbf{N}=32)$

\begin{tabular}{|l|c|c|c|c|}
\hline \multirow{2}{*}{$\begin{array}{c}\text { Causes of } \\
\text { Esophageal } \\
\text { Stricture }\end{array}$} & \multicolumn{2}{|c|}{ Site of Esophageal Stricture } & \multirow{2}{*}{ P-Value } \\
\cline { 2 - 4 } & Distal & Proximal & Total & \\
\hline Chemical Burn & $5(21.7 \%)$ & $18(78.3 \%)$ & 23 & \multirow{2}{*}{0.132} \\
\hline Esophageal Atresia & $0(0 \%)-$ & $4(100 \%)$ & 4 \\
\hline GERD\# & $\mathrm{I}(50.0 \%)$ & $\mathrm{I}(50.0 \%)$ & 2 & \\
\hline Congenital & $\mathrm{I}(100 \%)$ & $0(0 \%)$ & $\mathrm{I}$ & \\
\hline Achalasia & $\mathrm{I}(100 \%)$ & $0(0 \%)$ & $\mathrm{I}$ \\
\hline Foreign Body & $0(0 \%)$ & $\mathrm{I}(100 \%)$ & $\mathrm{I}$ & \\
\hline Total & $8(25 \%)$ & $24(75 \%)$ & 32 & \\
\hline
\end{tabular}

\# Gastro-esophageal Reflux Disease; \$: Chi Square Test

were enrolled from July 2019 to March 2020. Children who were lost to followup or whose parents/guardians did not give consent to be a part of this study were excluded. Patients with previous history of dilatations or surgery for esophageal strictures were also excluded. Diagnosis of ES was made as per clinical history, endoscopy and findings from contrast-enhanced radiological examination of the esophagus.

Initial assessment consisted of the review of patient's clinical history and of the contrast-enhanced radiological examination of the esophagus. Parents/ guardians of all study participants were informed about possible complications that might result from the treatment, and a written consent form was signed by parents before the procedure. The study protocol was approved by the Research Ethics Committee of the Institute (Ref. No.120, Dated:08-072019). Emergency treatment was given to all patients in the form of fluid and electrolyte balance and pain management. After that, patients were discharged and called for endoscopy and dilatation after 6 weeks. Demographic data of the patients like age, gender, different etiologies, location of the ES, as well as treatment outcome were recorded on a predesigned proforma. Follow ups were advised after every 2 weeks and all the children enrolled had a minimum follow up of 12 weeks.

Examinations were done under general anesthesia, with airway protection, and a minimum fasting period of six hours. On esophagoscopy, the location, diameter and macroscopic aspect of the stricture were assessed. After general anesthesia, endoscope was passed, stricture was located and length noted from bupper incisior. Guide wire was passed through stricture and dilatation was done with savary dilators no 7, 9 and II mm size. After the procedure, patients remained under observation at the endoscopy unit for two to three hours. Post operatively patient remained NPO for 4 hours while PPIs and fluids were administered. X-ray chest was done to rule out pneumothorax. Dilatation sessions were run at an average interval of 15 days, with the use of at most three dilators with progressively increasing diameters per session. Relief of dysphagia and weight gain during outpatient follow-up were used as clinical parameters to determine the response to treatment. Relief of dysphagia was assessed adopting "Swallowing Rating Scale" as recommended by "American SpeechLanguage-Hearing Association (AHA)". ' A patient was said to respond the treatment if he started taking solid diet and started gaining weight and height without need of dilatation for minimum 3 months. Weight gain was assessed according to WHO centile charts. Improvement of centiles was considered as sufficient weight gain (minimum I kg per month). Standard treatment protocols of the institution were followed for treatment of all the study cases.

SPSS version 24.0 was used for data handling and analysis. Frequencies and percentages were calculated for qualitative variables while mean and standard deviation were noted for quantitative variables. Chi square test was employed to compare the overall outcome with treatment choice as well as types of etiologies and their relation to outcomes. $P$ value less than or equal to 0.05 was considered as of statistical significance.

\section{RESULTS}

Out of 32 children, 19 (59.4\%) were males and 13 (40.6\%) were females. Age ranged from I- 15 years. Thirteen (40.62\%) patients ranged in age from I3 years, II (34.38\%) from 4-7 years, 6 (I8.75\%) from 8 -II years and 2 $(6.25 \%)$ from $12-15$ years. Mean age of the patients was $36.58 \pm 19.6$ months.

Chemical burn ( $n=23 ; 71.9 \%)$, esophageal atresia $(n=4 ; 12.5 \%)$ and gastroesophageal reflux disease (GERD) [n=2; 6.3\%] were the most frequent cause of ES. Congenital, achalasia and foreign body were the causes in I $(3.1 \%)$ case each.

Out of 32 cases of ES, 24 (75\%) had proximal and $8(25 \%)$ had distal stricture. There was no statistically significant ( $p$ value $=0.132$ ) relationship between causes and site of ES (Table I). Among 23 cases of chemical burn, 18 (78.3\%) had proximal involvement while 5 (21.7\%) involved distal esophagus. All four cases of esophageal atresia had involvement of proximal esophagus.

Out of 32 patients with ES, 10 (31.3\%) underwent dilatation, one $(3.1 \%)$ patient had surgery and 21 (65.6\%) required both dilatation and surgery. In patients with chemical burns, majority $(n=16 / 23 ; 69.6 \%)$ required both dilatation and surgery and 7 (30.4\%) patients underwent dilatation only. There was no significant relationship ( $p$ value $=0.415$ ) between causes of ES and types of treatment required (Table II).

Overall outcome of treatment options was good in $62.5 \%(n=20 / 32)$ patients, while $37.5 \%$ patients had no significant improvement with any treatment option. Out of 21 patients requiring both dilatation and surgery, outcome was good in $61.9 \%(n=13 / 21)$, while in patients having dilatation only, $70 \%$ $(n=7 / 10)$ had improved outcome $(p=0.385)$. Thoracotomy and esophagoplasty was done in one patient as endto-end anastomosis was not possible due to too short healthy esophagus. End to end anastomosis was done in 15 patients, all cured after surgery. Pneumothorax occurred in I patient as complication during the process of dilatation which was managed by chest tube insertion and oxygen therapy, and patient improved. 
TABLE II: RELATIONSHIP OF CAUSES AND TYPES OF TREATMENT OF ESOPHAGEAL STRICTURE $(\mathrm{N}=32)$

\begin{tabular}{|c|c|c|c|c|c|}
\hline \multirow{2}{*}{$\begin{array}{l}\text { Causes of } \\
\text { Esophageal } \\
\text { Stricture }\end{array}$} & \multicolumn{4}{|c|}{ Treatment Type } & \multirow[b]{2}{*}{ P Value $\$$} \\
\hline & Dilatation & Surgery & $\begin{array}{l}\text { Dilatation } \\
\text { \& Surgery }\end{array}$ & Total & \\
\hline Chemical Burn & $7(30.4 \%)$ & $0(0 \%)$ & $16(69.6 \%)$ & 23 & \multirow{6}{*}{0.415} \\
\hline Esophageal Atresia & $2(50.0 \%)$ & I (25.0\%) & $\mathrm{I}(25.0 \%)$ & 4 & \\
\hline GERD ${ }^{\#}$ & $\mathrm{I}(50.0 \%)$ & $0(0 \%)-$ & $\mathrm{I}(25.0 \%)$ & 2 & \\
\hline Congenital & $0(0 \%)$ & $0(0 \%)$ & I (I00\%) & I & \\
\hline Achalasia & $0(0 \%)$ & $0(0 \%)$ & I (I00\%) & 1 & \\
\hline Foreign Body & $0(0 \%)$ & $0(0 \%)$ & $\mathrm{I}(100 \%)$ & $\mathrm{I}$ & \\
\hline Total & 10 & 1 & 21 & 32 & \\
\hline
\end{tabular}

Outcome in patients with chemical burns was good in $69.6 \%(n=16 / 23)$ cases. There was no statistically significant difference $(p=0.438)$ in outcome among patients having different etiology of ES (Table III).

Mortality was reported in $3.1 \%$ $(n=1 / 32)$ of patients.

\section{DISCUSSION}

This study was planned to present local experience of management of ES in pediatric patients from a tertiary care children hospital of Multan, Pakistan. In our setup chemical burn and esophageal atresia were the commonest causes of ES. Majority had involvement of proximal esophagus. Dilatation and surgery were performed in almost two-third of cases and dilatation in about one third cases. Outcome of all procedures was good in around sixty percent cases and had no significant relationship with causes and site of ES or types of treatment.

Children with ES have high rates of morbidity and weight loss, malnutrition, food impaction as well as pulmonary aspiration are some of the commonest consequences. ${ }^{10}$ The results of this study were supposed to highlight important aspects of $E S$ among pediatric population which would further help us reducing the morbidity as well as mortality associated with ES in our local population.

In the present study, it was noted that most of the children, $59.4 \%$ were male. A study conducted by Bazrafshan A, et al from Mashad, Iran" noted $56 \%$ of the children having ES to be male which is very close to the current findings. Elhalaby EA et $\mathrm{al}^{\prime 2}$ also noted most of the cases having ES to be male.

Mean age among the current study participants was noted to be $36.58 \pm 19.6$ months. Study from Iran" found mean age of the children with ES to be $25.8 \pm 29.7$ months which is lower than what we noted in the present study. On the other hand, a study from Jordan, ${ }^{13}$ noted mean age of the children with ES to be 3.2 years which is quite close to what we found in the present work. Difference in different sets of populations regarding time of possible intervention in children having ES represents variation.
In the present study, it was noted that mean 18.24 \pm 15.8 dilatations were done in patients undergoing dilatations. These results are very similar to previous findings" where mean number of $20.1 \pm 17.3$ dilatations were required by each children. It has also been shown by other researchers that cases having corrosives injuries need frequent dilatations. $^{14}$

Chemical burn, followed by esophageal atresia were found to be the most frequent cause of ES, in $23(71.9 \%)$ and $4(12.5 \%)$ respectively. Our results are well aligned with regional data where a study from India ${ }^{15}$ noted corrosive strictures to be the most common (50.5\%) cause of ES among children. Our findings are somewhat different to what has been noted in Iran and South Africa where esophageal atresia and GERD have been found to be the commonest etiologies for ES. ${ }^{11,16}$

In the current work, we did not find any relationship of causes and site of ES. Bazrafshan A et al., from Iran" noted proximal esophagus to be the most frequent site of ES. The same study also noted all cases of esophageal atresia surgery related ES to have stricture site proximal esophagus which correlates really well with the present finding. We noted $62.5 \%$ of the children to have recovery which shows that good outcomes can be achieved among children having ES. It was also seen that most of the children, 2 I (65.6\%) were treated by the combination of dilatation and surgery. In the current study, we did not find any significant relationship between outcome and type of

TABLE III: RELATIONSHIP OF TREATMENT TYPES AND CAUSES OF ESOPHAGEAL STRICTURE WITH OUTCOME (N=32)

\begin{tabular}{|c|c|c|c|c|c|}
\hline \multirow{2}{*}{\multicolumn{2}{|c|}{ Variables }} & \multicolumn{3}{|c|}{ Treatment Outcome } & \multirow[b]{2}{*}{ p-value $\$$} \\
\hline & & \multirow{2}{*}{$\begin{array}{c}\begin{array}{c}\text { Improved } \\
(\mathbf{n}=\mathbf{2 0})\end{array} \\
7(70.0 \%)\end{array}$} & \multirow{2}{*}{$\begin{array}{c}\begin{array}{c}\text { Not Improved } \\
(\mathrm{n}=12)\end{array} \\
3(30.0 \%)\end{array}$} & \multirow{2}{*}{$\begin{array}{c}\begin{array}{c}\text { Total } \\
(\mathrm{n}=32)\end{array} \\
10\end{array}$} & \\
\hline \multirow{3}{*}{ Treatment Types } & Dilatation & & & & \multirow{3}{*}{0.385} \\
\hline & Surgery & $0(0 \%)$ & $\mathrm{I}(100 \%)$ & $\mathrm{I}$ & \\
\hline & Dilatation and Surgery & $13(6 \mid .9 \%)$ & $8(38.1 \%)$ & 21 & \\
\hline \multirow{6}{*}{$\begin{array}{l}\text { Causes of } \\
\text { Esophageal } \\
\text { Stricture }\end{array}$} & Chemical Burn & $16(69.6 \%)$ & $7(30.4 \%)$ & 23 & \multirow{6}{*}{0.438} \\
\hline & Esophageal Atresia & $2(50.0 \%)$ & $2(50.0 \%)$ & 4 & \\
\hline & GERD\# & $\mathrm{I}(50.0 \%)$ & $\mathrm{I}(50.0 \%)$ & 2 & \\
\hline & Congenital & $0(0 \%)$ & $\mathrm{I}(100 \%)$ & I & \\
\hline & Achalasia & $0(0 \%)$ & $\mathrm{I}(100 \%)$ & $\mathrm{I}$ & \\
\hline & Foreign Body & $\mathrm{I}(\mathrm{I} 00 \%)$ & $0(0 \%)$ & I & \\
\hline
\end{tabular}

\# Gastro-esophageal Reflux Disease; \$: Chi Square Test 
treatment. These findings stand similar to what has been found previously among children having ES." Literature reports that endoscopic dilatation with savary dilators is safer and has very few technical malfunctions in comparison to surgical methods. ${ }^{17}$ Each patient having ES should be treated on individual basis according to his/her own condition even if they are having the same etiology. As majority of the patients in the current study had chemical burn as the commonest etiology, dilatation is the first therapeutic option for strictures and bougies should be considered for the children as was done in the present study. It is crucial to avoid malnutrition, especially in developing countries where management strategies are influenced by malnutrition and poor clinical conditions. ${ }^{18}$ In the present study, $50.0 \%$ of the cases with esophageal atresia were treated with dilatation. A study having cases of esophageal atresia, showed that dilation had better outcome as compared to other modes of treatment. ${ }^{19}$ Best time of dilatation and frequency is not well known. Literature reports 2 retrospective findings where no difference in the outcome or complication rates were noted among children treated differently. ${ }^{20,21}$

Being the $I^{\text {st }}$ analysis in the recent years about the etiologies as well as the outcome of pediatric population suffering with $E S$ is one of the strengths of this study. We tried to find out the common causes as well different types of treatment and their relationship with the outcome. The current study should lay the foundation of many aspects of children with ES in Pakistan.

\section{LIMITATIONS}

Relatively shorter duration of follow up was one of the major limitations of this study. Limited number of cases was another limitation of this study. Further longitudinal studies involving multiple centers and different sets of population will help us knowing more about the etiological as well as treatment aspects of ES among children.

\section{CONCLUSION}

Chemical burn and esophageal atresia were the most common causes of esophageal strictures among pediatric patients in our setup. Outcome of all procedures was good in $62.5 \%$ cases. No significant relationship of outcome was observed with causes and site of ES or types of treatment. It is recommended that child with ES should be treated on individual basis according to his/her own condition even if they are having the same etiology.

\section{ACKNOWLEDGMENT}

The authors would like to thank $M$. Aamir (Bahawalpur, Pakistan) for his volunteer assistance in statistical analysis of this research. The authors are also thankful to participants of this study.

\section{REFERENCES}

I. Qiu Y, Shi R. Roles of Steroids in Preventing Esophageal Stricture after Endoscopic Resection. Can J Gastroenterol Hepatol 2019:53808/5. https://doi.org/ 10.1155/2019/5380815

2. Desai JP, Moustarah F. Esophageal Stricture. [Updated 2019 Nov 25]. In: StatPearls [Internet]. Treasure Island (FL): StatPearls Publishing; Jan 2020. Accessed on: Available from URL: https://www.ncbi.nlm.nih.gov/ books/NBK542209/

3. Ruigómez AI, García Rodríguez LA, Wallander MA, Johansson S, Eklund S. Esophageal stricture: incidence, treatment patterns, and recurrence rate. Am J Gastroenterol 2006; I0 I (I 2):2685-92. https://doi.org/ |0.1 I I I/j. I572-0241.2006.00828.x

4. Thomson $M$, Tringali $A$, Dumonceau JM, Tavares M, Tabbers MM, Furlano $\mathrm{R}$, et al. Paediatric gastrointestinal endoscopy: European society for paediatric gastroenterology hepatology and nutrition and European society of gastrointestinal endoscopy guidelines. J Pediatr Gastroenterol Nutr 2017;64:133-53. https://doi. org/ I0. 1097/MPG.000000000000 I 408

5. Pearson EG, Downey EC, Barnhart DC, Scaife ER, Rollins MD, Black RE, et al. Reflux esophageal stricture-a review of 30 years' experience in children. J Pediatr Surg 2010;45: 2356-60. https://doi.org/10.1016/ j.jpedsurg.2010.08.033
6. Pasha SF, Acosta RD, Chandrasekhara V, Chathadi KV, Decker GA, Early DS, et al. The role of endoscopy in the evaluation and management of dysphagia. Gastrointest Endosc 20|4;79(2):|9|-20I. https://doi.org/ 10.1016/j.gie.2013.07.042

7. Lamoria S, De A, Agarwal S, Singh Lamba BM, Sharma V. Peptic esophageal stricture in an adolescent with Barrett's esophagus. Int J Adolesc Med Health 2016;29(5). https://doi.org/10.15/5/ijamh2015-0106

8. Vandenplas Y. Management of Benign Esophageal Strictures in Children. Pediatr Gastroenterol Hepatol Nutr 20 I 7;20(4):2 I I-5.

9. Dungan S, Gregorio D, Abrahams T, Harrison B, Abrahams J, Brocato D, et al. Comparative validity of the American Speech-LanguageHearing Association's National Outcomes Measurement System, Functional Oral Intake Scale, and GCodes to Mann Assessment of Swallowing Ability Scores for dysphagia. Am J Speech Lang Pathol 2019;28(2):424-9. https://doi.org/ 10.1044/2018_AJSLP-18-0072

I0. Inuwa IM, Ismail JA, Oyebanji NT, Anyanwu LJC, Aji SA, Mohammad $M A$, et al. Management of long segment corrosive esophageal stricture in children and adults: A 5 years' review. J Clin Sci 2019;16:8I6. https://doi.org//0.4/03/ jcls.jcls_24_19

I I. Bazrafshan A, Heydarian F, Sadeghi M, Rahmani Sh. Esophageal Strictures in Children. Patient Saf Qual Improv 20 I4;2(3): 123-5.

12. Elhalaby EA, Elbarbary MM, Hashish AA, Kaddah SN, Hamza AF, Waheeb $S M$, et al. Congenital esophageal stenosis: to dilate or to resect. Ann Pediatr Surg 2006;2(I):2-9.

13. Saleem MM. Acquired oesophageal strictures in children: emphasis on the use of string-guided dilatations. Singapore Med J 2009;50( I ):82-6.

14. Kay M, Wyllie R. Caustic ingestions in children. Curr Opin Pediatr 2009;2I:65I-4. https://doi.org/ I0.1097/MOP.0b0 I 3e32832e2764 
15. Poddar U, Thapa BR. Benign esophageal strictures in infants and children: results of Savary-Gilliard bougie dilation in 107 Indian children. Gastrointest Endosc 2001;54(4): 480-4. https://doi.org//0.1067/ mge.200I.II8253

16. Moumin OS, Hadley GP. An audit of the management of oesophageal stricture in children in Durban, KwaZulu-Natal Province, South Africa. S Afr J Child Health 2017; I I (2):7I-4. https://doi.org//0.7/96/ SAJCH.20I7.vI Ii2.II 79

17. Lang T, Hümmer HP, Behrens R. Balloon dilation is preferable to bougienage in children with esophageal atresia. Endoscopy 200I;33:329-35. https://doi.org/ |0.1055/s-200|-|369|

18. Contini S, Scarpignato C. Caustic injury of the upper gastrointestinal tract: a comprehensive review. World J Gastroenterol 20 I 3; I 9(25): 39/8-30. https://doi.org/10.3748/ wjg.v19.i25.3918

19. Thyoka M, Timmis A, Mhango T, Roebuck DJ. Balloon dilatation of anastomotic strictures secondary to surgical repair of oesophageal atresia: a systematic review. Pediatr Radiol 2013;43:898-901. https://doi.org/

\section{I0.1007/s00247-0|3-2693-2}

20. Koivusalo A, Pakarinen MP, Rintala RJ. Anastomotic dilatation after repair of esophageal atresia with distal fistula. Comparison of results after routine versus selective dilatation. Dis Esophagus 2009;22: 190-4. https://doi.org//0.1।11/ j. I 442-2050.2008.00902.x

21. Berger M, Ure B, Lacher $M$. Mitomycin $C$ in the therapy of recurrent esophageal strictures: hype or hope? Eur J Pediatr Surg 2012;22:109-16. https://doi.org/ $10.1055 / \mathrm{s}-0032-1311695$

\section{AUTHOR'S CONTRIBUTION}

All the authors have made substantial contributions to the manuscript as under:

IH \& MTA: Acquisition of data, drafting the manuscript, critical review, approval of final version to be published

HS: Conception and study design, critical review, approval of final version to be published

S] \& GKK: Analysis and interpretation of data, drafting the manuscript, approval of final version to be published

MA: Acquisition of data, drafting the manuscript, approval of final version to be published

Authors agree to be accountable for all aspects of the work in ensuring that questions related to the accuracy or integrity of any part of the work are appropriately investigated and resolved.

CONFLICT OF INTEREST
Authors declared no conflict of interest
GRANT SUPPORT AND FINANCIAL DISCLOSURE
Authors have declared no specific grant for this research from any
funding agency in the public, commercial or not-for-profit sectors
CONFLICT OF INTEREST

\section{GRANT SUPPORT AND FINANCIAL DISCLOSURE}

funding agency in the public, commercial or not-for-profit sectors

\section{DATA SHARING STATEMENT}

The data that support the findings of this study are available from the corresponding author upon reasonable request.

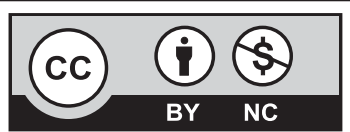

This is an Open Access article distributed under the terms of the Creative Commons Attribution-Non Commercial 2.0 Generic License.
KMUJ web address: www.kmuj.kmu.edu.pk

Email address: kmuj@kmu.edu.pk 